\title{
Conservation of T cell epitopes between seasonal influenza viruses and the novel influenza A H7N9 virus
}

\author{
Huawei Mao ${ }^{1,2}$, Hui-Ling Yen ${ }^{3}$, Yinping Liu ${ }^{2}$, Yu-Lung Lau ${ }^{2}$, J.S. Malik Peiris ${ }^{3 凶}$, Wenwei Tu${ }^{2 \bowtie}$
}

1. Department of Paediatrics, The University of Hong Kong - Shenzhen Hospital, Shenzhen, China;

2. Department of Paediatrics \& Adolescent Medicine, The University of Hong Kong, Hong Kong SAR, China;

3. Centre of Influenza Research, School of Public Health, The University of Hong Kong, Hong Kong SAR, China.

A novel avian influenza A (H7N9) virus recently emerged in the Yangtze River delta and caused diseases, often severe, in over 130 people. This H7N9 virus appeared to infect humans with greater ease than previous avian influenza virus subtypes such as H5N1 and H9N2. While there are other potential explanations for this large number of human infections with an avian influenza virus, we investigated whether a lack of conserved T-cell epitopes between endemic H1N1 and H3N2 influenza viruses and the novel H7N9 virus contributes to this observation. Here we demonstrate that a number of T cell epitopes are conserved between endemic H1N1 and H3N2 viruses and H7N9 virus. Most of these conserved epitopes are from viral internal proteins. The extent of conservation between endemic human seasonal influenza and avian influenza H7N9 was comparable to that with the highly pathogenic avian influenza H5N1. Thus, the ease of inter-species transmission of H7N9 viruses (compared with avian H5N1 viruses) cannot be attributed to the lack of conservation of such $\mathrm{T}$ cell epitopes. On the contrary, our findings predict significant T-cell based cross-reactions in the human population to the novel H7N9 virus. Our findings also have implications for H7N9 virus vaccine design.

KEYWORDS H7N9; influenza virus; T cell epitope; conservation; clinical phenotype; vaccine; immunity

\section{INTRODUCTION}

In March 2013, human infections with a novel avian influenza H7N9 virus were identified in China (Gao R, et al., 2013). Although other H7 subtype infections in humans have been detected before, this is the first report of human infection with an H7N9 influenza virus. As of $12^{\text {th }}$ August 2013, a total of 135 laboratory-confirmed cases of human H7N9 infection have been reported to WHO, 44 of these being fatal (WHO, 2013). Phylogenetic anal-

Received: 5 May 2014, Accepted: 10 June 2014

Published online: 17 June 2014

$\triangle$ Correspondence:

Wenwei Tu, Phone: +852-2819-9357, Fax: +852-2819-8142,

Email: wwtu@hkucc.hku.hk

J.S. Malik Peiris, Phone: +852-39177537, Email: malik@hkucc.hku.hk ysis indicated that this novel virus is a reassortant virus, with the hemagglutinin (HA) gene originating from a duck influenza virus, neuraminidase (NA) gene from a wild bird virus and six internal genes derived from poultry avian H9N2 viruses (Lam T T, et al., 2013; Liu D, et al., 2013).

Human infections with H7N9 virus were first clustered around the Yangtze River delta followed by occurrence in the neighbouring provinces (Cowling B J, et al., 2013; Li Q, et al., 2013). Most of hospitalized patients had severe illness, ranging from pneumonia to ARDS and multi-organ dysfunction sometimes necessitating mechanical ventilation or extra corporeal membrane oxygenation (Chen Y, et al., 2013; Gao H N, et al., 2013). Despite these high fatality rates, a recent study indicated that there may be many milder cases that were not reported and human infections with H7N9 virus may be 
less severe than previously reported (Yu H, et al., 2013).

$\mathrm{T}$ cell immunity plays important roles in host defenses against influenza virus infection. While it is generally believed that T-cells do not prevent virus infection in the way that antibody does, cross-reactive $\mathrm{T}$ cells, including CD4 and CD8 T cells, are believed to enhance virus clearance and reduce severity of illness, even in the absence of virus-specific antibodies (McMichael A J, et al., 1983). In the $2009 \mathrm{H} 1 \mathrm{~N} 1$ pandemic (pdmH1N1) outbreak, we analyzed the conserved CD8 T cell epitopes in pdmH1N1 virus, and demonstrated that the conserved epitope-specific $\mathrm{T}$ cells established by seasonal influenza virus could cross react against the pandemic virus, which might contribute to the milder pandemic H1N1 illness overall and the lower infection attack rate in young adults even though they did not have detectable cross-neutralizing antibody (Tu W, et al., 2010). In this study, we analyzed the conservation of $\mathrm{T}$ cell epitopes of seasonal influenza virus in $\mathrm{H} 7 \mathrm{~N} 9$ virus, aiming to provide some insight into pre-existing immunity to the H7N9 illness.

\section{METHODS}

Total human $\mathrm{T}$ cell epitopes of influenza A viruses in the Immune Epitope Database (IEDB) (http://www. iedb.org) were retrieved, which is a publicly available database of epitopes for infectious agents (Vita R, et al., 2010). The epitopes that induced a positive T-cell response were included for analysis. The presence of these epitopes in seasonal influenza viruses including A/Brisbane/59/2007 (H1N1) and A/Brisbane/10/2007 (H3N2) were examined for each virus and then for the two viruses together. The conservation of these pooled $\mathrm{T}$ cell epitopes in the novel avian H7N9 (A/Anhui/1/2013), 2009 pandemic (A/California/07/2009(H1N1)) (pdmH1N1), avian H9N2 (A/Quail/Hong Kong/G1/97) and highly pathogenic avian H5N1 (A/common magpie/ Hong Kong/5052/2007) viruses were further analyzed respectively. The epitopes with $100 \%$ conservation were included for analysis. The distribution of epitopes in different viral proteins was checked. Chi square test was employed to compare the conservation of $\mathrm{T}$ cell epitopes in H7N9 virus with that in other virus.

\section{RESULTS}

\section{MHC class I-restricted CD8 T cell epitope analysis}

All experimentally determined $\mathrm{T}$ cell epitopes were retrieved from IEDB database. A total of 223 MHC class I-restricted epitopes with positive $\mathrm{T}$ cell response have been reported in influenza A viruses. We examined the presence of these CD8 T cell epitopes in seasonal influenza $\mathrm{H} 1 \mathrm{~N} 1$ and $\mathrm{H} 3 \mathrm{~N} 2$ virus subtypes (prior to emergence of pdmH1N1). As shown in Table 1, 151 epitopes were detected in seasonal H1N1 and H3N2 viruses. Of these, 81 were shared by both of them, 44 were unique to H1N1 and 26 unique to H3N2 virus. Most of the epitopes were located in viral internal NP, M1 and PB1 proteins, while few were in surface HA and NA proteins. Among the 151 seasonal influenza epitopes, $68.9 \%(104 / 151)$ were conserved in the novel H7N9 virus. A similar conservation level of these epitopes was also detected in pdmH1N1 $(69.5 \%), \mathrm{H} 9 \mathrm{~N} 2(68.2 \%)$ and $\mathrm{H} 5 \mathrm{~N} 1$ (71.5\%) viruses. The conserved epitopes were mainly derived from viral NP, M1 and PB1 proteins (Table 2). As currently, a large number of humans have been exposed to pdmH1N1 prior to H7N9 outbreak, we further examined how many epitopes of seasonal H1N1, H3N2 plus pdmH1N1 viruses are conserved in the avian viruses. As shown in Table 3, $67.7 \%(113 / 167), 67.7 \%(113 / 167)$ and $73.1 \%(122 / 167)$ of these CD8 T cell epitopes were invariant in H7N9, $\mathrm{H} 9 \mathrm{~N} 2$ and $\mathrm{H} 5 \mathrm{~N} 1$ virus respectively.

\section{MHC class II-restricted CD4 T cell epitope analysis}

We next examined the conservation of CD4 T cell epitopes. $687 \mathrm{MHC}$ class II-restricted epitopes with pos-

Table 1. CD8 T cell epitopes in seasonal H1N1 \& H3N2 viruses

\begin{tabular}{lcccc}
\hline & Unique H1N1 & Shared & Unique H3N2 & Total \\
& & & & \\
\hline M1 & 4 & 28 & 3 & 35 \\
M2 & 0 & 1 & 1 & 2 \\
NP & 22 & 13 & 17 & 52 \\
PA & 3 & 8 & 0 & 11 \\
PB1 & 4 & 26 & 3 & 33 \\
PB2 & 2 & 3 & 2 & 7 \\
NS1 & 4 & 0 & 0 & 4 \\
NS2 & 0 & 2 & 0 & 2 \\
HA & 3 & 0 & 0 & 3 \\
NA & 2 & 0 & 0 & 2 \\
Total & 44 & 81 & 26 & 151 \\
\hline
\end{tabular}

Table 2. Conservation of seasonal CD8 T cell epitopes in other viruses

\begin{tabular}{lccccc}
\hline \multicolumn{2}{c}{$\begin{array}{c}\text { Seasonal } \\
\text { pitopes }\end{array}$} & $\begin{array}{c}\text { Conserved } \\
\text { in H7N9 }\end{array}$ & $\begin{array}{c}\text { Conserved } \\
\text { in pdmH1N1 }\end{array}$ & $\begin{array}{c}\text { Conserved } \\
\text { in H9N2 }\end{array}$ & $\begin{array}{c}\text { Conserved } \\
\text { in H5N1 }\end{array}$ \\
\hline M1 & 35 & 24 & 26 & 28 & 24 \\
M2 & 2 & 0 & 0 & 0 & 0 \\
NP & 52 & 35 & 36 & 31 & 35 \\
PA & 11 & 9 & 8 & 6 & 9 \\
PB1 & 33 & 27 & 28 & 29 & 30 \\
PB2 & 7 & 5 & 4 & 5 & 5 \\
NS1 & 4 & 1 & 0 & 1 & 1 \\
NS2 & 2 & 2 & 1 & 2 & 1 \\
HA & 3 & 1 & 1 & 1 & 2 \\
NA & 2 & 0 & 1 & 0 & 1 \\
Total & 151 & 104 & 105 & 103 & 108 \\
\hline & & & & &
\end{tabular}


itive $\mathrm{T}$ cell response were obtained from the database, of which 199 and 189 epitopes were present in seasonal H1N1 and H3N2 virus respectively. Among them 71 were shared by both seasonal influenza viruses. Most of the epitopes were derived from HA, NP, M2 and NA proteins (Table 4). The conservation of these seasonal influenza viral epitopes in avian influenza viruses was further analyzed. As shown in Table 5, 23.3\% (74/317) of these epitopes were conserved in H7N9 virus. Compared to H7N9 virus, a similar conservation level was shown in H9N2 $(28.4 \%, 90 / 317)$ and H5N1 $(25.6 \%, 81 / 317)$ virus, but a much higher level $(31.9 \%, 101 / 317, \mathrm{p}<0.05)$ was conserved in pdmH1N1 virus. As with the CD8 T cell epitopes, the conserved CD4 T cell epitopes were mainly located in M1, NP and PB1 proteins. Few epitopes of surface HA and NA proteins were invariant in the avian influenza viruses. We also analyzed the conservation of CD4 T cell epitopes of seasonal H1N1, H3N2 plus pdmH1N1 viruses in avian influenza virus. As shown in Table 6, 22.1\% (81/367), 27.2\% (100/367) and 27.8\% $(102 / 367)$ of these epitopes remained invariant in H7N9, $\mathrm{H} 9 \mathrm{~N} 2$ and $\mathrm{H} 5 \mathrm{~N} 1$ virus respectively.

Table 3. Conservation of seasonal plus pdmH1N1 CD8 epitopes in other viruses

\begin{tabular}{lcccc}
\hline & $\begin{array}{c}\text { Seasonal plus } \\
\text { pdmH1N1 } \\
\text { epitopes }\end{array}$ & $\begin{array}{c}\text { Conserved } \\
\text { in H7N9 }\end{array}$ & $\begin{array}{c}\text { Conserved } \\
\text { in H9N2 }\end{array}$ & $\begin{array}{c}\text { Conserved } \\
\text { in H5N1 }\end{array}$ \\
\hline M1 & 37 & 24 & 28 & 25 \\
M2 & 3 & 1 & 1 & 1 \\
NP & 60 & 40 & 36 & 42 \\
PA & 13 & 10 & 8 & 11 \\
PB1 & 33 & 27 & 29 & 30 \\
PB2 & 7 & 5 & 5 & 5 \\
NS1 & 5 & 2 & 2 & 2 \\
NS2 & 3 & 3 & 3 & 2 \\
HA & 3 & 1 & 1 & 2 \\
NA & 3 & 0 & 0 & 2 \\
\hline Total & 167 & 113 & 113 & 122 \\
\hline
\end{tabular}

Table 4. CD4 T cell epitopes in seasonal H1N1 \& H3N2 viruses

\begin{tabular}{lcccc}
\hline & Unique H1N1 & Shared & Unique H3N2 & Total \\
\hline M1 & 15 & 45 & 8 & 68 \\
M2 & 1 & 0 & 0 & 1 \\
NP & 23 & 15 & 25 & 63 \\
PA & 1 & 2 & 1 & 4 \\
PB1 & 5 & 8 & 2 & 15 \\
PB2 & 1 & 0 & 2 & 3 \\
NS1 & 6 & 1 & 3 & 10 \\
NS2 & 2 & 0 & 1 & 3 \\
HA & 53 & 0 & 57 & 110 \\
NA & 21 & 0 & 19 & 40 \\
Total & 128 & 71 & 118 & 317 \\
\hline & & & & \\
\hline
\end{tabular}

\section{DISCUSSION}

In this study, we analyzed the T cell epitopes in $\mathrm{H} 7 \mathrm{~N} 9$ influenza virus and found that around $70 \%$ and $20 \%$ of experimentally determined CD8 and CD4 T cell epitopes of seasonal influenza virus were conserved in the novel H7N9 virus. Most of the conserved epitopes were derived from viral internal proteins. The degree of conservation of CD8 epitopes between seasonal influenza and novel H7N9 did not differ from that seen with pd$\mathrm{mH} 1 \mathrm{~N} 1$, avian $\mathrm{H} 9 \mathrm{~N} 2$ or avian $\mathrm{H} 5 \mathrm{~N} 1$ viruses. Thus lack of cross-reactive CD8 epitopes could not explain the apparently high susceptibility of humans to novel H7N9 virus. However, the number of CD4 T cell epitopes conserved between seasonal influenza $\mathrm{H} 1 \mathrm{~N} 1$ and $\mathrm{H} 3 \mathrm{~N} 2$ and H7N9 virus $(23.3 \%)$ was lower than the conservation seen between seasonal influenza and pdmH1N1 (31.9\%) but comparable to that seen in H9N2 (28.4\%) and H5N1 $(25.6 \%)$ viruses. Thus it is conceivable that there was more CD4 $\mathrm{T}$ cell cross-protection against the pdmH1N1

Table 5. Conservation of seasonal CD4 T cell epitopes in other viruses

\begin{tabular}{lccccc}
\hline & $\begin{array}{c}\text { Seasonal } \\
\text { epitopes }\end{array}$ & $\begin{array}{c}\text { Conserved } \\
\text { in H7N9 }\end{array}$ & $\begin{array}{c}\text { Conserved } \\
\text { in pdmH1N1 } 1\end{array}$ & $\begin{array}{c}\text { Conserved } \\
\text { in H9N2 }\end{array}$ & $\begin{array}{c}\text { Conserved } \\
\text { in H5N1 }\end{array}$ \\
\hline M1 & 68 & 32 & 40 & 40 & 35 \\
M2 & 1 & 0 & 0 & 0 & 0 \\
NP & 63 & 24 & 25 & 24 & 21 \\
PA & 4 & 4 & 3 & 4 & 3 \\
PB1 & 15 & 11 & 9 & 13 & 12 \\
PB2 & 3 & 1 & 1 & 2 & 2 \\
NS1 & 10 & 1 & 2 & 2 & 3 \\
NS2 & 3 & 1 & 0 & 2 & 1 \\
HA & 110 & 0 & 18 & 0 & 0 \\
NA & 40 & 0 & 3 & 3 & 4 \\
Total & 317 & 74 & 101 & 90 & 81 \\
\hline
\end{tabular}

Table 6. Conservation of seasonal plus pdmH1N1 CD4 epitopes in other viruses

$\begin{array}{cccc}\begin{array}{c}\text { Seasonal plus } \\ \text { pdmH1N1 }\end{array} & \begin{array}{c}\text { Conserved } \\ \text { in H7N9 }\end{array} & \begin{array}{c}\text { Conserved } \\ \text { in H9N2 }\end{array} & \begin{array}{c}\text { Conserved } \\ \text { in H5N1 }\end{array}\end{array}$

\begin{tabular}{lcccc}
\hline M1 & 72 & 32 & 42 & 39 \\
M2 & 1 & 0 & 0 & 0 \\
NP & 71 & 28 & 30 & 27 \\
PA & 4 & 4 & 4 & 3 \\
PB1 & 17 & 13 & 14 & 14 \\
PB2 & 4 & 2 & 3 & 3 \\
NS1 & 10 & 1 & 2 & 3 \\
NS2 & 3 & 1 & 2 & 1 \\
HA & 123 & 0 & 0 & 0 \\
NA & 62 & 0 & 3 & 12 \\
Total & 367 & 81 & 100 & 102 \\
\hline
\end{tabular}


virus when it emerged in 2009 compared with what is likely for novel $\mathrm{H} 7 \mathrm{~N} 9$ or for other avian viruses $\mathrm{H} 9 \mathrm{~N} 2$ or H5N1. Hence it may be possible that the milder disease course of pdmH1N1 virus may be contributed by cross-reactive T-cell epitopes. However, it is unlikely that the ease with which H7N9 virus infects humans compared with other avian viruses such as $\mathrm{H} 5 \mathrm{~N} 1$, can be explained on a similar basis.

Both humoral and $\mathrm{T}$ cell immunity are responsible for human defense against influenza virus infection. $\mathrm{T}$ cells promote viral clearance and reduce illness severity (Mbawuike I N, et al., 2007; McMichael A J, et al., 1983; Webby R J, et al., 2003). Unlike humoral immunity that protects against a specific influenza viral strain alone, $T$ cells could cross-react against across serologically distinct viruses of different HA subtypes. The cross-protection of $\mathrm{T}$ cells has been demonstrated in humans in vivo by the Cleveland family study (Boon A C, et al., 2004; Jameson J, et al., 1999). Humans who have not been exposed to avian influenza A (H5N1) virus do have cross- reactive memory $\mathrm{T}$ cells to a wide range of $\mathrm{H} 5 \mathrm{~N} 1$ peptides (Lee L Y, et al., 2008; Roti M, et al., 2008). In 2009 H1N1 pandemic outbreak, we also demonstrated the cross-reactivity of conserved epitope-specific $\mathrm{T}$ cells against pdmH1N1 virus (Tu W, et al., 2010). For the novel H7N9 influenza virus, although pre-existing humoral immunity is low in the general population (Boni M F, et al., 2013), here we showed that most CD8 and less CD4 $\mathrm{T}$ cell epitopes of seasonal influenza virus were conserved in H7N9 virus. It could be expected that these conserved epitope-specific $\mathrm{T}$ cells established by seasonal influenza virus may provide some protection against H7N9 virus, which might explain the presence of mild infection cases.

Although many of the hospitalized patients with H7N9 virus infection had severe illness, several cases were identified via influenza-like illness surveillance network and presented with mild clinical phenotype, even did not require hospitalization. This implied that a substantial number of symptomatic infections with mild to moderate illness remained unconfirmed. It was estimated that about 1500-27000 symptomatic H7N9 infections might have occurred as of May 28, 2013 (Yu H, et al., 2013). The H7N9 infection may indeed be less serious than previously reported, and the symptomatic case fatality risk was estimated to be 160-2800 per 100000 symptomatic cases (Cowling B, et al., 2013; Yu H, et al., 2013). Well designed sero-epidemiology studies may help clarify these issues. Identification of mild H7N9 infection cases is challenging due to the detection bias. Generally, case detection is typically biased to severe patients with mild cases having lower probability of being detected (Viboud C, et al., 2013). Therefore, the so far detected several mild cases may be just the tip of an iceberg of
H7N9 infections at the community (Ip D K, et al., 2013). The case detection bias also leads to an overestimation of fatality risk. In $2009 \mathrm{H} 1 \mathrm{~N} 1$ pandemic, the case-fatality estimates rapidly declined with increased data from sero-epidemiological studies defining the true infection attack rate in the population (Viboud C, et al., 2013). Similarly, it could be expected that the estimated fatality risk of $\mathrm{H} 7 \mathrm{~N} 9$ virus may decrease with greater information, which indeed has been demonstrated by a preliminary study (Yu H, et al., 2013).

Like avian H5N1 infection, most of patients with H7N9 infection who were hospitalized for medical care had severe illness, although both of the two viruses had conserved $\mathrm{T}$ cell epitopes that are shared with seasonal influenza virus. The inpatient fatality risk of H7N9 infection was estimated to be $36 \%$ on admission to hospital (Yu $\mathrm{H}$, et al., 2013). Indeed, the clinical phenotype of influenza illness depends on host defense mechanisms as well as the virus itself. In comparison to avian H5N1 virus, the H7N9 virus also induced significant hyperinflammatory responses in hosts, although the extent of such responses appeared to be less extreme compared with H5N1 virus (Chan M, et al., 2013). Substantial increased levels of serum cytokines and chemokines, including IP10, MIG, MIP-1 $\beta$, MCP-1, IL-6, IL-8 and IFN- $\alpha$, were detected in patients with $\mathrm{H} 7 \mathrm{~N} 9$ infection, compared to healthy controls (Chen Y, et al., 2013; Zhou J, et al., 2013). Hypercytokinemia may partly contribute to the clinical severity in H7N9 infection, as seen in $\mathrm{H} 5 \mathrm{~N} 1$ infection.

As the general human population does not have pre-existing humoral immunity against H7N9 and present inactivated seasonal vaccination does not provide cross-protection (Boni M F, et al., 2013; Zhou J, et al., 2013) development of specific vaccines to prepare for a potential outbreak of H7N9 infection are underway. Current influenza vaccine strategy targets an antibody response against surface HA antigen. Recent in silico analysis showed that the HA protein of H7N9 virus has low $\mathrm{T}$ cell epitope content and poor immunogenicity (De Groot A S, et al., 2013) which is compatible with our findings that no CD4 T cell epitopes in HA and NA proteins of seasonal influenza virus were conserved in $\mathrm{H} 7 \mathrm{~N} 9$ virus. The CD4 T cell response is required for the development of antibody response. Thus, these data indicate that H7N9 influenza vaccine would be of relatively low efficacy if it were based on current vaccine strategy. However, here we further demonstrate that many $\mathrm{T}$ cell epitopes of internal proteins of seasonal influenza virus were conserved in the novel H7N9 virus. It has been shown that $\mathrm{T}$ cell immunity can provide cross-protection against serologically distinct influenza viruses (Boon A C, et al., 2004; Jameson J, et al., 1999). Therefore, including more conserved $\mathrm{T}$ cell epitopes of internal proteins in 
the vaccine would be an applicable and attractive way to develop an effective H7N9 vaccine.

\section{ACKNOWLEDGMENT}

This work was supported in part by General Research Fund, Research Grants Council of Hong Kong (HKU 780113M); Area of Excellence program (AoE/M-12/06), University Grants Committee of Hong Kong SAR; Research Fund for the Control of Infectious Diseases, Hong Kong SAR government (11100742).

\section{COMPLIANCE WITH ETHICS GUIDELINES}

All the authors declare that they have no competing interest. This article does not contain any studies with human or animal subjects performed by the any of the authors.

\section{AUTHOR CONTRIBUTIONS}

HM, YLL, JSMP and WT designed the study. HM, HLY and YL performed the study and analyzed the data. HM, YLL, JSMP and WT wrote the paper. All authors read and approved the final manuscript.

\section{REFERENCES}

Boni M F, Chau N V, Dong N, Todd S, Nhat N T, de Bruin E, van Beek J, Hien N T, Simmons C P, Farrar J, and Koopmans M. 2013. Population-Level Antibody Estimates to Novel Influenza A/H7N9. J Infect Dis, 208: 554-558.

Boon A C, de Mutsert G, van Baarle D, Smith D J, Lapedes A S, Fouchier R A, Sintnicolaas K, Osterhaus A D, and Rimmelzwaan G F. 2004. Recognition of homo- and heterosubtypic variants of influenza A viruses by human CD8+ T lymphocytes. J Immunol, 172: 2453-2460.

Chan M, Chan R, Chan L, Mok C, Hui K, Fong J, Tao K, Poon L, Nicholls J, Guan Y, and Peiris J. 2013. Tropism and innate host responses of a novel avian influenza A H7N9 virus: an analysis of ex-vivo and in-vitro cultures of the human respiratory tract. Lancet Respiratory Disease, Published online July 25, 2013, DOI: 10.1016/S2213-2600(13)70138-3.

Chen Y, Liang W, Yang S, Wu N, Gao H, Sheng J, Yao H, Wo J, Fang Q, Cui D, Li Y, Yao X, Zhang Y, Wu H, Zheng S, Diao H, Xia S, Zhang Y, Chan K H, Tsoi H W, Teng J L, Song W, Wang P, Lau S Y, Zheng M, Chan J F, To K K, Chen H, Li L, and Yuen K Y. 2013. Human infections with the emerging avian influenza A H7N9 virus from wet market poultry: clinical analysis and characterisation of viral genome. Lancet, 381: 1916-1925.

Cowling B, Freeman G, Wong J, Wu P, Liao Q, Lau E, Wu J, Fielding R, and Leung G. 2013. Preliminary inferences on the age-specific seriousness of human disease caused by avian influenza A(H7N9) infections in China, March to April 2013. Euro Surveill, 18: 20475.

Cowling B J, Jin L, Lau E H, Liao Q, Wu P, Jiang H, Tsang T K, Zheng J, Fang V J, Chang Z, Ni M Y, Zhang Q, Ip D K, Yu J, Li Y, Wang L, Tu W, Meng L, Wu J T, Luo H, Li Q, Shu Y, Li Z, Feng Z, Yang W, Wang Y, Leung G M, and Yu H. 2013. Comparative epidemiology of human infections with avian influenza A H7N9 and H5N1 viruses in China: a population-based study of laboratory-confirmed cases. Lancet, 382: 129-137.

De Groot A S, Ardito M, Terry F, Levitz L, Ross T M, Moise L, and Martin W. 2013. Low immunogenicity predicted for emerging avian-origin H7N9: Implication for influenza vaccine design. Hum Vaccin Immunother, 9: 950-956.

Gao H N, Lu H Z, Cao B, Du B, Shang H, Gan J H, Lu S H, Yang Y D, Fang Q, Shen Y Z, Xi X M, Gu Q, Zhou X M, Qu H P, Yan Z, Li F M, Zhao W, Gao Z C, Wang G F, Ruan L X, Wang W H, Ye J, Cao H F, Li X W, Zhang W H, Fang X C, He J, Liang W F, Xie J, Zeng M, Wu X Z, Li J, Xia Q, Jin Z C, Chen Q, Tang C, Zhang Z Y, Hou B M, Feng Z X, Sheng J F, Zhong N S, and Li L J. 2013. Clinical findings in 111 cases of influenza A (H7N9) virus infection. N Engl J Med, 368: 2277-2285.

Gao R, Cao B, Hu Y, Feng Z, Wang D, Hu W, Chen J, Jie Z, Qiu H, Xu K, Xu X, Lu H, Zhu W, Gao Z, Xiang N, Shen Y, He Z, Gu Y, Zhang Z, Yang Y, Zhao X, Zhou L, Li X, Zou S, Zhang Y, Li X, Yang L, Guo J, Dong J, Li Q, Dong L, Zhu Y, Bai T, Wang S, Hao P, Yang W, Zhang Y, Han J, Yu H, Li D, Gao G F, Wu G, Wang Y, Yuan Z, and Shu Y. 2013. Human infection with a novel avian-origin influenza A (H7N9) virus. N Engl J Med, 368: 1888-1897.

Ip D K, Liao Q, Wu P, Gao Z, Cao B, Feng L, Xu X, Jiang H, Li M, Bao J, Zheng J, Zhang Q, Chang Z, Li Y, Yu J, Liu F, Ni M Y, Wu J T, Cowling B J, Yang W, Leung G M, and Yu H. 2013. Detection of mild to moderate influenza A/H7N9 infection by China's national sentinel surveillance system for influenza-like illness: case series. BMJ, 346: f3693.

Jameson J, Cruz J, Terajima M, and Ennis F A. 1999. Human CD8+ and CD4+ T lymphocyte memory to influenza A viruses of swine and avian species. J Immunol, 162: 7578-7583.

Lam T T, Wang J, Shen Y, Zhou B, Duan L, Cheung C L, Ma C, Lycett S J, Leung C Y, Chen X, Li L, Hong W, Chai Y, Zhou L, Liang H, Ou Z, Liu Y, Farooqui A, Kelvin D J, Poon L L, Smith D K, Pybus O G, Leung G M, Shu Y, Webster R G, Webby R J, Peiris J S, Rambaut A, Zhu H, and Guan Y. 2013. The genesis and source of the H7N9 influenza viruses causing human infections in China. Nature: doi:10.1038/nature12515.

Lee L Y, Ha do L A, Simmons C, de Jong M D, Chau N V, Schumacher R, Peng Y C, McMichael A J, Farrar J J, Smith G L, Townsend A R, Askonas B A, Rowland-Jones S, and Dong T. 2008. Memory T cells established by seasonal human influenza A infection cross-react with avian influenza A (H5N1) in healthy individuals. J Clin Invest, 118: 3478-3490.

Li Q, Zhou L, Zhou M, Chen Z, Li F, Wu H, Xiang N, Chen E, Tang F, Wang D, Meng L, Hong Z, Tu W, Cao Y, Li L, Ding F, Liu B, Wang M, Xie R, Gao R, Li X, Bai T, Zou S, He J, Hu J, $\mathrm{Xu}$ Y, Chai C, Wang S, Gao Y, Jin L, Zhang Y, Luo H, Yu H, Gao L, Pang X, Liu G, Shu Y, Yang W, Uyeki T M, Wang Y, Wu F, and Feng Z. 2013. Preliminary Report: Epidemiology of the Avian Influenza A (H7N9) Outbreak in China. N Engl J Med: DOI: 10.1056/NEJMoa1304617.

Liu D, Shi W, Shi Y, Wang D, Xiao H, Li W, Bi Y, Wu Y, Li X, Yan J, Liu W, Zhao G, Yang W, Wang Y, Ma J, Shu Y, Lei F, and Gao G F. 2013. Origin and diversity of novel avian influenza A H7N9 viruses causing human infection: phylogenetic, structural, and coalescent analyses. Lancet, 381: 1926-1932.

Mbawuike I N, Zhang Y, and Couch R B. 2007. Control of mucosal virus infection by influenza nucleoprotein-specific CD8+ cytotoxic T lymphocytes. Respir Res, 8: 44.

McMichael A J, Gotch F M, Noble G R, and Beare P A. 1983. Cytotoxic T-cell immunity to influenza. N Engl J Med, 309: 13-17.

Roti M, Yang J, Berger D, Huston L, James E A, and Kwok W 
W. 2008. Healthy human subjects have CD4+ T cells directed against H5N1 influenza virus. J Immunol, 180: 1758-1768.

Tu W, Mao H, Zheng J, Liu Y, Chiu S S, Qin G, Chan P L, Lam K T, Guan J, Zhang L, Guan Y, Yuen K Y, Peiris J S, and Lau Y L. 2010. Cytotoxic T lymphocytes established by seasonal human influenza cross-react against 2009 pandemic H1N1 influenza virus. J Virol, 84: 6527-6535.

Viboud C, and Simonsen L. 2013. Timely estimates of influenza A H7N9 infection severity. Lancet, 382: 106-108.

Vita R, Zarebski L, Greenbaum J A, Emami H, Hoof I, Salimi N, Damle R, Sette A, and Peters B. 2010. The immune epitope database 2.0. Nucleic Acids Res, 38: D854-D862.

Webby R J, Andreansky S, Stambas J, Rehg J E, Webster R G, Doherty P C, and Turner S J. 2003. Protection and compensation in the influenza virus-specific CD8+ T cell response. Proc Natl Acad Sci U S A, 100: 7235-7240.
WHO. 2013. Number of confirmed human cases of avian influenza $\mathrm{A}(\mathrm{H} 7 \mathrm{~N} 9)$ reported to WHO. http://www.who. int/influenza/human_animal_interface/influenza_h7n9/09 ReportWebH7N9Number.pdf.

Yu H, Cowling B J, Feng L, Lau E H, Liao Q, Tsang T K, Peng Z, Wu P, Liu F, Fang V J, Zhang H, Li M, Zeng L, Xu Z, Li Z, Luo H, Li Q, Feng Z, Cao B, Yang W, Wu J T, Wang Y, and Leung G M. 2013. Human infection with avian influenza A H7N9 virus: an assessment of clinical severity. Lancet, 382: 138-145.

Zhou J, Wang D, Gao R, Zhao B, Song J, Qi X, Zhang Y, Shi Y, Yang L, Zhu W, Bai T, Qin K, Lan Y, Zou S, Guo J, Dong J, Dong L, Zhang Y, Wei H, Li X, Lu J, Liu L, Zhao X, Li X, Huang W, Wen L, Bo H, Xin L, Chen Y, Xu C, Pei Y, Yang Y, Zhang X, Wang S, Feng Z, Han J, Yang W, Gao G F, Wu G, Li D, Wang Y, and Shu Y. 2013. Biological features of novel avian influenza A (H7N9) virus. Nature, 499: 500-503. 